\title{
The Variation Characteristics of Asian Surface Temperature and Precipitation in the Early 21 st Century
}

\author{
Kuo Wang, ${ }^{1}$ Guolin Feng, ${ }^{2}$ Tianshu Ye, ${ }^{3}$ Xujia Wang, ${ }^{4}$ and Peipei Liu ${ }^{5}$ \\ ${ }^{1}$ Zhejiang Climate Center, Zhejiang Meteorological Bureau, Hangzhou 310017, China \\ ${ }^{2}$ Laboratory for Climate Studies, National Climate Center, China Meteorological Administration, Beijing 100081, China \\ ${ }^{3}$ Hydrology and Water Resources Survey Bureau of Liaoning Province, Shenyang 110003, China \\ ${ }^{4}$ College of Atmospheric Sciences, Lanzhou University, Lanzhou 730000, China \\ ${ }^{5}$ Meteorological Bureau of Ankang, Ankang 725000, China
}

Correspondence should be addressed to Guolin Feng; fenggl@cma.gov.cn

Received 28 October 2015; Accepted 2 March 2016

Academic Editor: Amit Chakraborty

Copyright ( 2016 Kuo Wang et al. This is an open access article distributed under the Creative Commons Attribution License, which permits unrestricted use, distribution, and reproduction in any medium, provided the original work is properly cited.

Based on the analysis of the feature of Asian continent becoming cold in the early 21st century winter under the background of global warming, the Asian Warming Hole (AWH) index is proposed in this paper to measure the intensity during the cold events process. Result shows that the Asian continent is indeed experiencing a cold stage in the early 21st century winter, but it is just in a cold phase and will become warmer in the future. In recent years the activity of the winter cold events has an obvious quasifour-year cycle, which can be reflected by atmospheric circulation, and AO (Arctic Oscillation) may play a very important role. It is credible that Asian surface temperature will be higher in the coming 3-4 years compared with 2011 winter, signifying that the precipitation may increase correspondingly.

\section{Introduction}

Today, global warming has become a consensus for most meteorologists since industrialisation, which is attributed to both anthropogenic forcing and natural variability [1-3]. For example, climate models show that global warming will continue if greenhouse gases (GHGs) enhanced and atmospheric prominent decadal variabilities have been proposed as key factors in climate simulations [4]. However, because of the differences in local regional condition, global warming is inconsistent everywhere. In 2001 Houghton et al. proposed the cooling trend in center North American continent in summer [5]. Subsequently, Pan et al. implied "Warming Hole" for the summer cold regions of North America continent and simulated the "North American Warming Hole" feedback mechanism by local greenhouse gas model; the effects of evaporation, precipitation, and low level jet (LLJ) are analyzed in this region carefully [6]. Kunkel et al. used super multimodel ensemble (MME) program to elaborate the predictability of North American Warming Hole and further discuss the reason for this phenomenon which is from natural variability or boundary condition forcing [7]. The local relative cooling events under global warming have caused widespread concern all over the world [8].

Climate variability consists of climate signals and noise. Climate signals are variations forced by slowly varying anomalous boundary conditions of the climate system [911]. When the proportion of the climate signal variability is high enough to overcome the destruction effects of noise, the climate anomaly may exhibit a particular degree of predictability [12]. Additionally, climate system does not advance gradually; it changes from one relative steady stage to another in a short time, which is known as an abrupt climate change $[13,14]$. Previous studies about developing detection method and dealing with the transition process have shown that some signals can be detected during (before) abrupt climate change [15-17].

How to detect the signal of global (trend) and regional climate change is always a central issue in recent climate change studies [18]. Wallace et al. proposed partial least squares (PLS) 
to apply dynamical adjustment to remove the surface air temperature trend over extratropical Northern Hemisphere continents during the cold season [19]. Guan et al. followed this idea to investigate the recent warming trend slowdown (WTS) and confirmed that dynamically induced variability caused the WTS over the Northern Hemisphere [20]. It is well known that the globe is getting warmer at a fast speed in the last 30 years, and a lot of papers have discussed the possible mechanism of "hiatus" in the 21st century [21-24]. However, there is still less concern on this phenomenon in Asia.

Since the 21st century, Asian cold disaster occurred frequently in winter, which makes people's life inconvenient and influences the economic development. For example, most areas of South China suffered historically rare cold disaster in January 2008 [25-27], and the Northeast and North China witnessed sustained snow storm from November 2009 to April 2010 [28]. Previous results have analyzed each cold case from different angles to explain the mechanism [29-31]. However, the overall study of cold events in a long timescale in Asian winter is still lacking under the background of global warming, which is corresponding well with the "hiatus." What is the relationship between cold events and global warming? Will the phenomenon still occur continually or not in the future? For answering these questions, this paper describes materials and methods firstly, defines Asian Warming Hole $(\mathrm{AWH})$ index to represent the variation of Asian surface temperature, analyzes the characteristics of Asian continent cold events in the early 21st century under global warming, investigates the linkage of $\mathrm{AWH}$ to atmospheric circulation, and summarizes conclusions at last.

\section{Methods and Data}

This paper mainly used NECP/NCAR (National Centers for Environmental Prediction/National Center for Atmospheric Research) Reanalysis 2 monthly average global temperature and geopotential data [32], which has a spatial resolution of $2.5^{\circ} \times 2.5^{\circ}$ for $1979-2012$, with 17 levels from $1000 \mathrm{hPa}$ to $10 \mathrm{hPa}$. All data have been calculated anomalously (relative 1979-2012). The AO index used in this study is published by CPC (Climate Prediction Center).

The methods include empirical orthogonal function (EOF) decomposition to get domain and principal components (PC), correlation analysis, and wavelet analysis. EOF is used in this study to depict the features of meteorological fields, and it is useful to simplify the complexity in calculation. The basic premise of EOF is that a series of meteorological fields are decomposed into linear combinations of eigenvectors and corresponding time series [33]. EOF is expressed as

$$
X_{m \times n}=V_{m \times m} Z_{m \times n}
$$

where $X_{m \times n}$ is a collection of spatiotemporal series with $m$ spatial dimensions that are each observed $n$ times $(t=$ $1, \ldots, t=n)$ and arrays $V_{m \times m}$ and $Z_{m \times n}$ are called empirical orthogonal functions of space and time (PC), respectively.
The winter time present here is from December this year to February next year.

\section{Results and Discussion}

3.1. Characteristics of Cold Event in the Early 21st Century. Figure 1 is EOF1 spatial pattern and its PC for Asian continent temperature anomaly at $1000 \mathrm{hPa}$ level for nearly 30 years. As can be seen, there is a strong negative center over northwest Asia $\left(60^{\circ}-70^{\circ} \mathrm{N}, 90^{\circ}-120^{\circ} \mathrm{E}\right)$, which makes the high latitude regions in a cold pattern. Combining with PC1 (Figure 1(b)), Asian region shows a warming trend from last century to the beginning of 21st century, which is corresponding well to the trend of global warming. However, when the PC1 in winter time (Figure 1(c)) is selected, the interdecadal trend of winter temperature is not consistent with the trend of global warming. Asian winter temperature is in cold phase before 90 s and then becomes warm until 21st century, but it returns to a cold trend since 2007. From historical observation trend and 9-point running mean, the $\mathrm{PCl}$ changes to positive since 2010, reaches a peak in 2011, and maintains a positive phase, which indicates that, in recent 4 years, the winter in Asian continent is indeed in a cold phase. Since the beginning of the 21st century, there exists a cooling trend in the Asian continent temperature in winter under the background of global warming, which is similar to the North American continent temperature in summer. An important issue presented by this phenomenon is to analyze the characteristics.

3.2. Characteristics of $A W H$. In this study the key region of temperature field for Asian winter cold event is identified by 2007-2011 minus 2002-2006, using the period of cold phase minus the former period. As shown in Figure 2(a) there is a significant negative region in central Asia, with the difference exceeding $-9^{\circ} \mathrm{C}$. As the "Warming Hole" phenomenon from North American continent, we define this region as the key area of $\mathrm{AWH}\left(75^{\circ} \mathrm{E}-125^{\circ} \mathrm{E}, 52.5^{\circ} \mathrm{N}-65^{\circ} \mathrm{N}\right)$, and the average over this region is defined as $\mathrm{AWH}$ index. The correlation coefficient between winter temperature field at $1000 \mathrm{hPa}$ level and AWH index is calculated as shown in Figure 2(b). The AWH index can capture the characteristics of winter temperature field in Asia because the correlation coefficient in most regions of Asian continent is above $99 \%$ confidence level.

Figure 3 shows the variation of AWH index; it is always in positive phase before 2007 except for 1980s and then begins to decline since 2007 turning to negative phase, which is similar to Figure 1(c) meaning that the AWH index can indicate the strength and cycle of Asian continent cold event. From historical data it is not the first time for AWH index in cold trend since 1979; comparing with a similar history period of 1983-1987, the 21st century cold event is colder and the duration is relatively longer.

The wavelet analysis of AWH index is calculated in Figure 4, which shows that there is a decadal cycle since early 1980s; and a significant 4-year cycle appears after early 21st century. Figure 1 has shown that in the beginning of the 21st century the Asian continent turns into negative phase, and cyclical activity is significantly enhanced with a new 


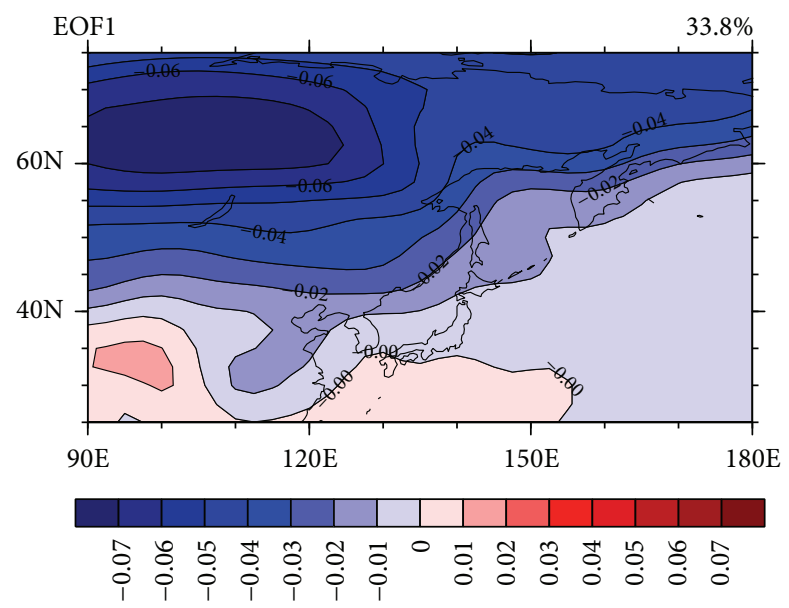

(a)

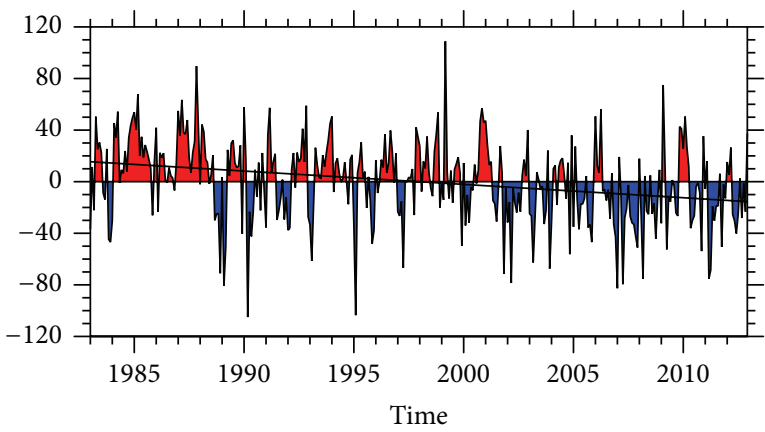

(b)

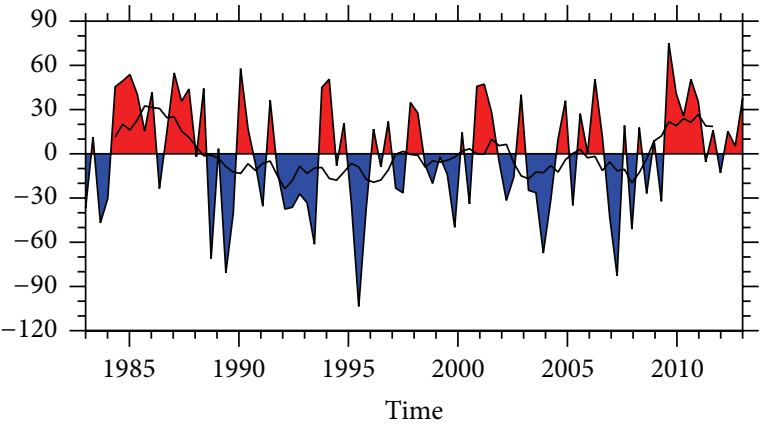

(c)

FIGURE 1: 1983-2012 Asian continent temperature anomaly field at $1000 \mathrm{hPa}$ level: (a) EOF1; (b) PC1: black solid line is linear trend; (c) PC1 in winter time: black solid line is 9-point running mean.

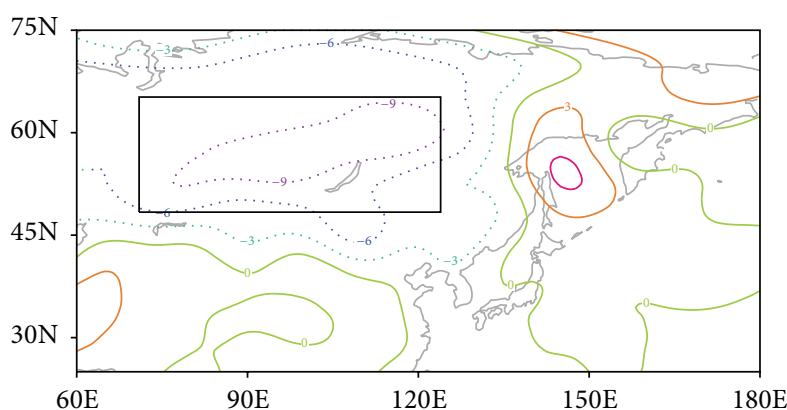

(a)

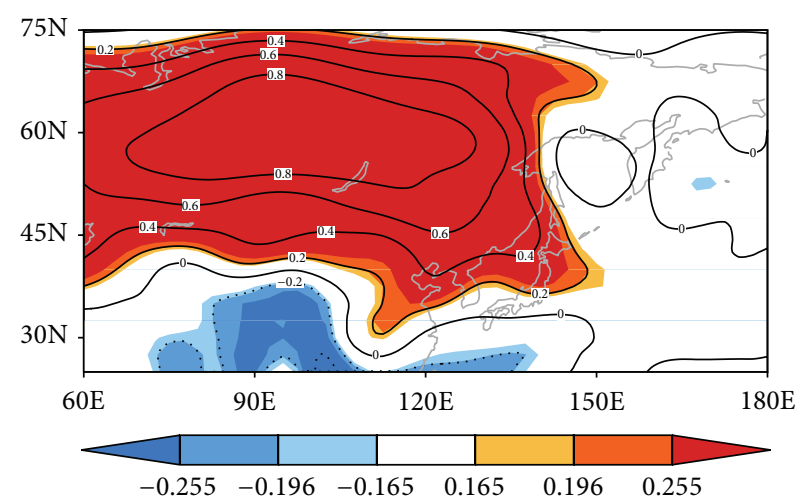

(b)

Figure 2: (a) The difference between the Asian winter temperature field at $1000 \mathrm{hPa}$ level: black box areas are key area; (b) correlation coefficient between winter temperature field at $1000 \mathrm{hPa}$ level and $\mathrm{AWH}$ index.

cycle. Therefore, the winter cold events still need to be paid attention to regarding their occurrence and development in this region in the future. The results of the trend and cycle of AWH index indicate that Asian winter temperature reaches its minimum value in 2011 and will be higher in the coming 3-4 years comparing with 2011 winter. Based on the above results it shows that the AWH index can well characterize the trends and intensity of the Asian continent cold events and it can measure the variation of winter temperature in this region.

3.3. The Relationship between AWH and Atmospheric Circulation. Previous studies have shown that there is a close relationship between Asian cold events and atmospheric 


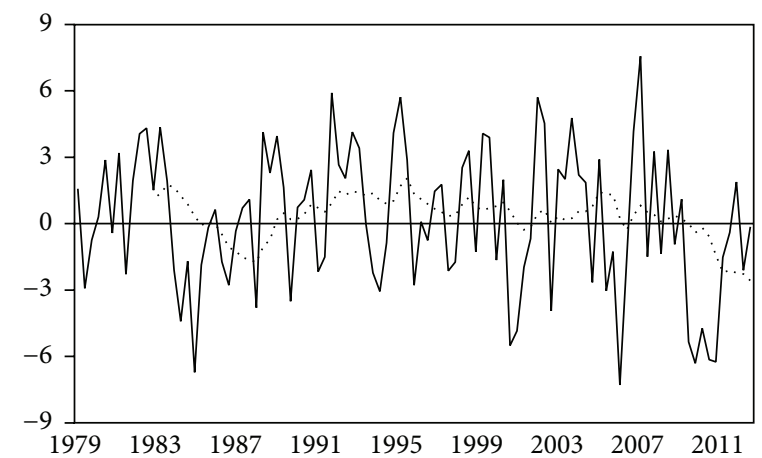

FIGURE 3: The variation of AWH index: the dotted line is 4-point running mean.

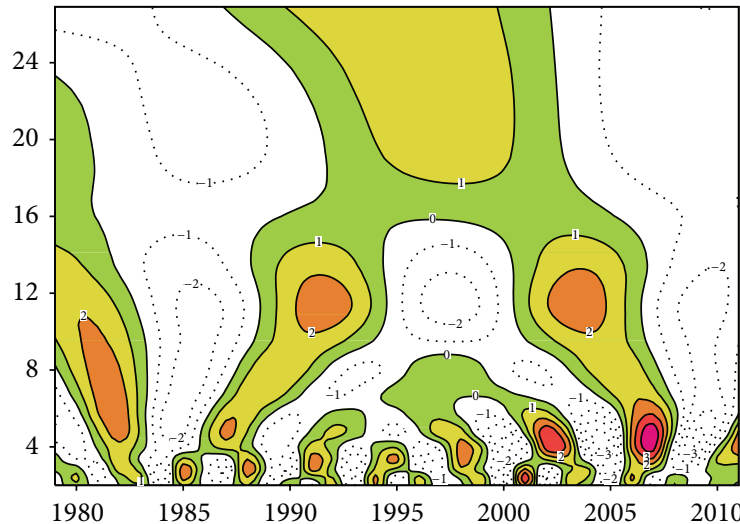

(a)

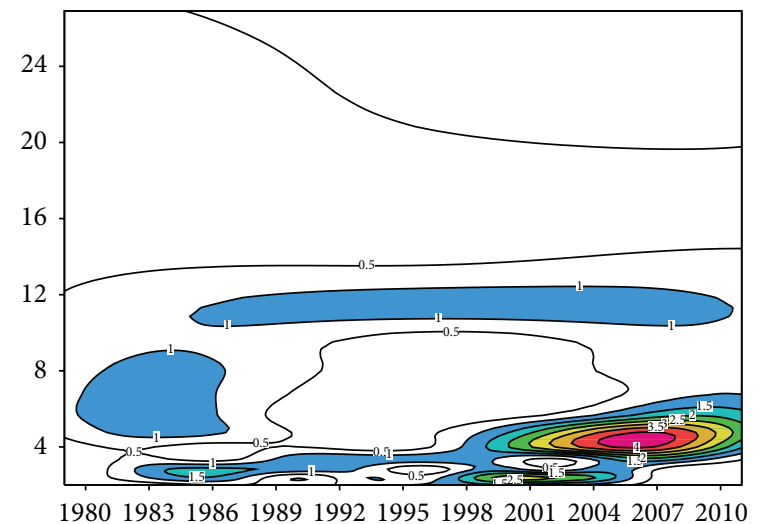

(b)

FIGURE 4: AWH index wavelet analysis: (a) real; (b) mode.

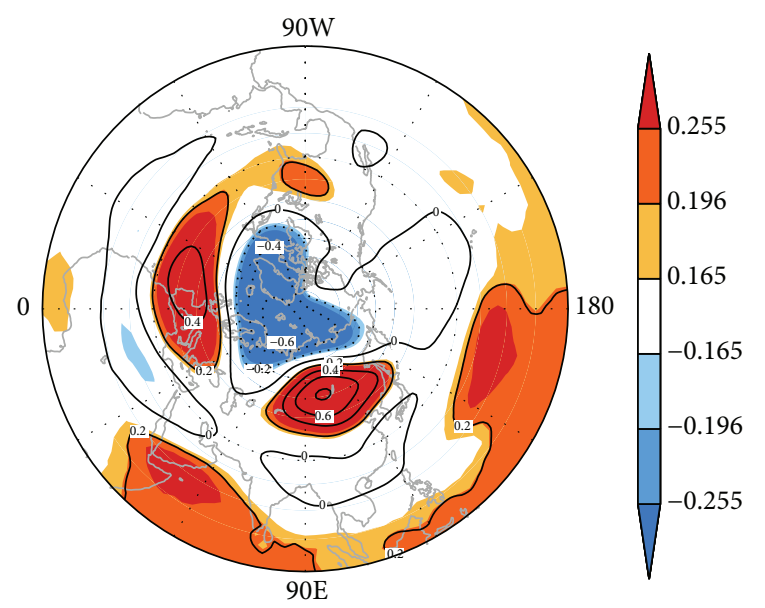

Figure 5: The correlation coefficient between AWH and geopotential field at $500 \mathrm{hPa}$ level.

circulation, such as AO and NAO (North Atlantic Oscillation) [34-37]. The atmospheric oscillation is a significant precursor factor, so the correlation coefficient between $\mathrm{AWH}$ index and geopotential field at $500 \mathrm{hPa}$ level is calculated, as shown in Figure 5. The different color represents the areas exceeding 90\%, 95\%, and 99\% confidence level separately

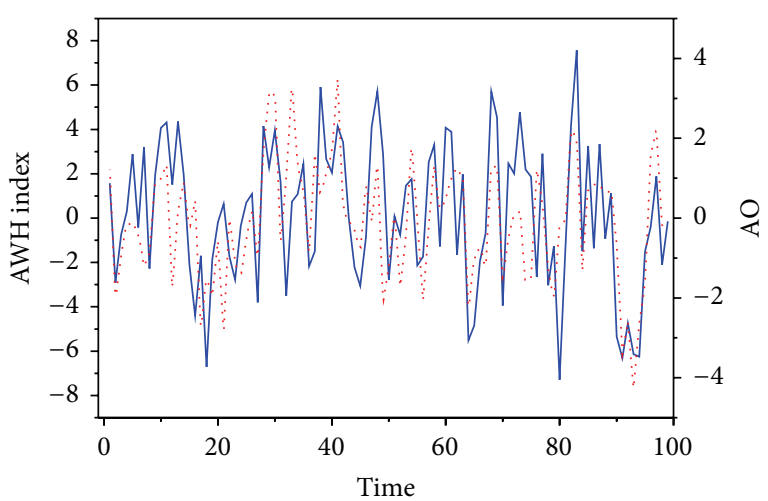

FIgURE 6: The variation of AWH index and AO monthly index in winter time. The blue line is AWH and the red dotted line is AO.

by $t$-test. In Figure 5, the correlation coefficients above $99 \%$ confidence level are mostly over high latitudes, which is like the AO pattern. There are negative center over polar vortex and two positive centers over Asian, Atlantic, and European areas in high latitudes. To prove whether $\mathrm{AWH}$ relates to $\mathrm{AO}$ well, Figure 6 is their variation in winter time. It is obvious that they are similar in cycle and trend during 99 months (33 years $\times 3$ months) and better consistent in recent years. These results mean that the Asian cold events can be reflected by 
atmospheric circulation, and AO may play a very important role.

\section{Conclusions}

In this paper we analyze the feature of Asian cold event in winter in the early 21st century under global warming, propose AWH index to measure the intensity of cold events in the process, and analyze the relationship between AWH index and atmospheric oscillation. Result shows that the winter temperature in Asian continent in the 21st century is indeed experiencing a cold phase under global warming, which is similar to the historical period of 1983-1987, but the intensity is stronger and lasts longer. The AWH index reaches its minimum value in 2011; combining with a significant fouryear period, the Asian temperature in winter will be warmer in next 3-4 years compared with 2011. The significant period of AWH index is a very important key to forecast the climate trend of Asian temperature in winter. The linkage of $\mathrm{AWH}$ to atmospheric circulation is close over high latitudes in the Northern Hemisphere, and AO may play a very important role. When AO is strong, it drives the cold air from high latitudes to low latitudes, reducing the temperature over Asia and triggering the occurrence of cold events.

From the observation data it is significant that Asia becomes warmer in winter these years after 2011, which proves the effectiveness of the method in this paper. When the surface warms, the water vapor concentration in the lower atmosphere increases by roughly $7 \%$ per ${ }^{\circ} \mathrm{C}$ of surface warming, which is consistent with the Clausius-Clapeyron equation and fixed relative humidity [38, 39]. So if the Asian temperature keeps in a warm phase, the moisture will increase in atmosphere, and the precipitation may increase correspondingly in the future. However, there is some uncertainty in this conclusion because the moisture is just one of the elements for precipitation; the atmospheric motion is also very important. Previous studies have shown that, under the background of global warming, most parts of Asia will be milder with enhanced moisture in winter, and the Asian winter monsoon (AWM) will weaken [40, 41]. Moreover, evaporation cannot be neglected as an essential part of the hydrologic cycle, which is of great significance for global hydrologic cycle and energy budget [42-45]. The evaporation is more complex and there is uncertainty in China under global warming [46].

Because this paper just investigates the features of temperature and atmosphere based on observation data, all the conclusions are statistical results by using statistical methods, and more critical research plans should be designed such as numerical simulation to explain the mechanism of this phenomenon in the future.

\section{Competing Interests}

The authors declare no competing interests.

\section{Authors' Contributions}

Guolin Feng planned the research. Xujia Wang and Tianshu Ye performed data analysis. Peipei Liu gave the suggestions about the structure of the paper. Kuo Wang wrote the first draft of the paper.

\section{Acknowledgments}

This work was supported by the National Basic Research Program of China (Grants nos. 2013CB430204 and 2012CB955902), the State Key Program of National Natural Science of China (Grant no. 41530531), the National Natural Science Foundation of China (Grant no. 41375078), and Climate Change Special Fund of China Meteorological Administration (Grant no. CCSF201427).

\section{References}

[1] IPCC, Climate Change 2007: The Physical Science Basis: Contribution of Working Group I to the Fourth Assessment Report of the Intergovernmental Panel on Climate Change, Cambridge University Press, Cambridge, UK, 2007.

[2] T. Otani, K. Toyosada, and Y. Shimizu, "Contribution of water saving to a stable power supply in Vietnam," Water, vol. 7, no. 6, pp. 2900-2907, 2015.

[3] P. D. Jones, M. New, D. E. Parker, S. Martin, and I. G. Rigor, "Surface air temperature and its changes over the past 150 years," Reviews of Geophysics, vol. 37, no. 2, pp. 173-199, 1999.

[4] J. Huang, K. Higuchi, and A. Shabbar, "The relationship between the North Atlantic Oscillation And E1 Niño-southern Oscillation," Geophysical Research Letters, vol. 25, no. 14, pp. 2707-2710, 1998.

[5] J. T. Houghton, Y. Ding, D. J. Griggs et al., Climate Change 2001: The Scientific Basis, Cambridge University Press, Cambridge, UK, 2001.

[6] Z. Pan, R. W. Arritt, E. S. Takle, W. J. Gutowski Jr., C. J. Anderson, and M. Segal, "Altered hydrologic feedback in a warming climate introduces a 'warming hole", Geophysical Research Letters, vol. 31, no. 17, Article ID L17109, 4 pages, 2004.

[7] K. E. Kunkel, X.-Z. Liang, J. H. Zhu, and Y. Lin, "Can CGCMs simulate the twentieth-century 'warning hole' in the Central United States?” Journal of Climate, vol. 19, no. 17, pp. 4137-4153, 2006.

[8] W. A. Robinson, R. Reudy, and J. E. Hansen, "General circulation model simulations of recent cooling in the east-central United States," Journal of Geophysical Research, vol. 107, no. 24, pp. 4-1-4-14, 2002.

[9] B. J. Hoskins and D. J. Karoly, "The steady linear response of a spherical atmosphere to thermal and orographic forcing," Journal of the Atmospheric Sciences, vol. 38, no. 6, pp. 1179-1196, 1981.

[10] X. Wang, Z. Zheng, G. Feng et al., "Summer prediction of sea surface temperatures in key areas in BCC_CSM model," Chinese Journal of Atmospheric Sciences, vol. 39, no. 2, pp. 271-288, 2015 (Chinese).

[11] T. Ye, Q. Shen, K. Wang, Z. Zhang, and J. Zhao, "Interdecadal change of the northward jump time of the western Pacific subtropical high in association with the Pacific decadal oscillation," Journal of Meteorological Research, vol. 29, no. 1, pp. 59-71, 2015.

[12] W. Y. Chen and H. M. Van den Dool, "Atmospheric predictability of seasonal, annual, and decadal climate means and the role of the ENSO cycle: a model study," Journal of Climate, vol. 10, no. 6, pp. 1236-1254, 1997. 
[13] W. He, S. Wan, Y. Jiang et al., "Detecting abrupt change on the basis of skewness: numerical tests and applications," International Journal of Climatology, vol. 33, no. 12, pp. 27132727, 2013.

[14] H. Wu, W. Hou, P.-C. Yan, Z.-S. Zhang, and K. Wang, "A study of the early warning signals of abrupt change in the Pacific decadal oscillation," Chinese Physics B, vol. 24, no. 8, Article ID 089201, 2015.

[15] P. C. Yan, G. L. Feng, and W. Hou, "A novel method for analyzing the process of abrupt climate change," Nonlinear Processes in Geophysics, vol. 22, no. 3, pp. 249-258, 2015.

[16] W. He, Q. Liu, Y. Jiang, and Y. Lu, "Comparison of performance between rescaled range analysis and rescaled variance analysis in detecting abrupt dynamic change," Chinese Physics B, vol. 24, no. 4, Article ID 049205, 2015.

[17] H. Jin, W. He, Q. Liu, J. Wang, and G. Feng, “The applicability of research on moving cutdata-approximate entropy on abrupt climate change detection," Theoretical and Applied Climatology, 2015.

[18] G. Y. Ren, Y. Q. Zhou, Z. Y. Chu et al., "Urbanization effects on observed surface air temperature trends in North China," Journal of Climate, vol. 21, no. 6, pp. 1333-1348, 2008.

[19] J. M. Wallace, Q. Fu, B. V. Smoliak, P. Lin, and C. M. Johanson, "Simulated versus observed patterns of warming over the extratropical Northern Hemisphere continents during the cold season," Proceedings of the National Academy of Sciences of the United States of America, vol. 109, no. 36, pp. 14337-14342, 2012.

[20] X. Guan, J. Huang, R. Guo, and P. Lin, “The role of dynamically induced variability in the recent warming trend slowdown over the Northern Hemisphere," Scientific Reports, vol. 5, Article ID 12669, 2015.

[21] Y. Kosaka and S.-P. Xie, "Recent global-warming hiatus tied to equatorial Pacific surface cooling," Nature, vol. 501, no. 7467, pp. 403-407, 2013.

[22] X. Chen and K.-K. Tung, "Varying planetary heat sink led to global-warming slowdown and acceleration," Science, vol. 345, no. 6199, pp. 897-903, 2014.

[23] D. R. Easterling and M. F. Wehner, "Is the climate warming or cooling?" Geophysical Research Letters, vol. 36, no. 8, Article ID L08706, 2009.

[24] F. Ji, Z. Wu, J. Huang, and E. P. Chassignet, "Evolution of land surface air temperature trend," Nature Climate Change, vol. 4, no. 6, pp. 462-466, 2014.

[25] Z. Gong, X. Wang, D. Cui et al., "The identification and changing characteristics of regional low temperature extreme events," Journal of Applied Meteorological Science, vol. 23, no. 2, pp. 195-204, 2012 (Chinese).

[26] Q. Feng, X. Guo, W. Zhao, Y. Qiu, and X. Zhang, "A comparative analysis of runoff and soil loss characteristics between 'extreme precipitation year' and 'normal precipitation year' at the plot scale: a case study in the Loess Plateau in China," Water, vol. 7, no. 7, pp. 3343-3366, 2015.

[27] K. Wang, G.-L. Feng, S.-P. Sun, and Z.-H. Zheng, "Study of the stable components in extended-range forecasting for the coming 10-30 days during the snow storm event in January 2008," Acta Physica Sinica, vol. 61, no. 10, Article ID 109201, 2012 (Chinese).
[28] Z. Wang, H. Zeng, G. Gao et al., "Climatic characters in 2010' China," Meteorological Monthly, vol. 37, no. 4, pp. 439-445, 2011 (Chinese).

[29] K. Wang, G.-L. Feng, Y.-X. Zeng, and X.-J. Wang, "Analysis of stable components in the extended-range forecast for the coming 10-30 days in winter 2010 and 2011," Chinese Physics B, vol. 22, no. 12, Article ID 129202, 2013.

[30] K. Wang, G.-L. Feng, S.-P. Sun, and Z.-H. Zheng, "Study of the stable components in extended-range forecasting for the coming 10-30 days during the snow storm event in November 2009," Acta Physica Sinica, vol. 61, no. 20, Article ID 209201, 2012 (Chinese).

[31] T. Feng, K. Zhang, H. Su, X. Wang, Z. Gong, and W. Zhang, "Spatiotemporal distribution characteristics and attribution of extreme regional low temperature event," Chinese Physics B, vol. 24, no. 10, Article ID 109201, 2015.

[32] M. Kanamitsu, W. Ebisuzaki, J. Woollen et al., "NCEP-DOE AMIP-II reanalysis (R-2)," Bulletin of the American Meteorological Society, vol. 83, no. 11, pp. 1631-1643, 2002.

[33] K. Wang, G. Feng, Y. Zeng, and Z. Li, "Extraction of 10-30day stable components from a Boreal atmosphere during ENSO phases," Discrete Dynamics in Nature and Society, vol. 2015, Article ID 919286, 6 pages, 2015.

[34] T. N. Stockdale, F. Molteni, and L. Ferranti, "Atmospheric initial conditions and the predictability of the Arctic Oscillation," Geophysical Research Letters, vol. 42, no. 4, pp. 1173-1179, 2015.

[35] J. Li, C. Sun, and F.-F. Jin, "NAO implicated as a predictor of Northern Hemisphere mean temperature multidecadal variability," Geophysical Research Letters, vol. 40, no. 20, pp. 54975502, 2013.

[36] S. Qiao, Z. Gong, G. Feng, and Z. Qian, "Relationship between cold winters over Northern Asia and the subsequent hot summers over mid-lower reaches of the Yangtze River valley under global warming," Atmospheric Science Letters, vol. 16, no. 4, pp. 479-484, 2015.

[37] G. Liu, G. Feng, Y. Qin, L. Cao, H. Yao, and Z. Liu, "Activity of cold vortex in Northeastern China and its connection with the characteristics of precipitation and circulation during 19602012," Journal of Geographical Sciences, vol. 25, no. 12, pp. 14231438, 2015.

[38] B. J. Soden, D. L. Jackson, V. Ramaswamy, M. D. Schwarzkopf, and $\mathrm{X}$. Huang, "The radiative signature of upper tropospheric moistening," Science, vol. 310, no. 5749, pp. 841-844, 2005.

[39] G. Vecchi, B. Soden, A. Wittenberg et al., "Weakening of tropical Pacific atmospheric circulation due to anthropogenic forcing," Nature, vol. 441, no. 7089, pp. 73-76, 2006.

[40] Z.-Z. Hu, L. Bengtsson, and K. Arpe, "Impact of global warming on the Asian winter monsoon in a coupled GCM," Journal of Geophysical Research Atmospheres, vol. 105, no. 4, Article ID 1999JD901031, pp. 4607-4624, 2000.

[41] M. E. Hori and H. Ueda, "Impact of global warming on the East Asian winter monsoon as revealed by nine coupled atmosphereocean GCMs," Geophysical Research Letters, vol. 33, no. 3, Article ID L03713, 2006.

[42] L. Sun and G. Wu, "Influence of land evapotranspiration on climate variations," Science in China, Series D: Earth Sciences, vol. 44, no. 9, pp. 838-846, 2001.

[43] T. Su, T. Feng, and G. Feng, "Evaporation variability under climate warming in five reanalyses and its association with pan 
evaporation over China," Journal of Geophysical Research, vol. 120, no. 16, pp. 8080-8098, 2015.

[44] G.-Q. Sun, S.-L. Wang, Q. Ren, Z. Jin, and Y.-P. Wu, "Effects of time delay and space on herbivore dynamics: linking inducible defenses of plants to herbivore outbreak," Scientific Reports, vol. 5, Article ID 11246, 2015.

[45] G.-Q. Sun, Z.-Y. Wu, Z. Wang, and Z. Jin, "Influence of isolation degree of spatial patterns on persistence of populations," Nonlinear Dynamics, vol. 83, no. 1, pp. 811-819, 2016.

[46] T. Su, G. Feng, J. Zhou, and M. Ye, “The response of actual evaporation to global warming in China based on six reanalysis datasets," International Journal of Climatology, vol. 35, no. 11, pp. 3238-3248, 2015. 


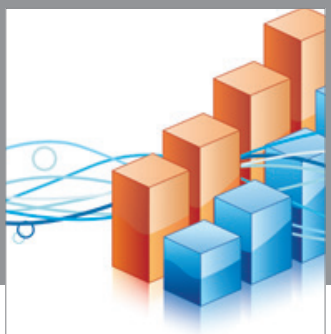

Advances in

Operations Research

vatem alat4

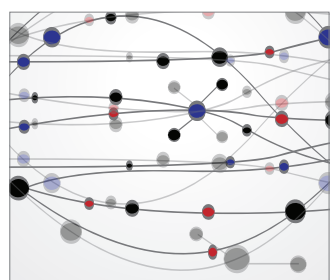

\section{The Scientific} World Journal
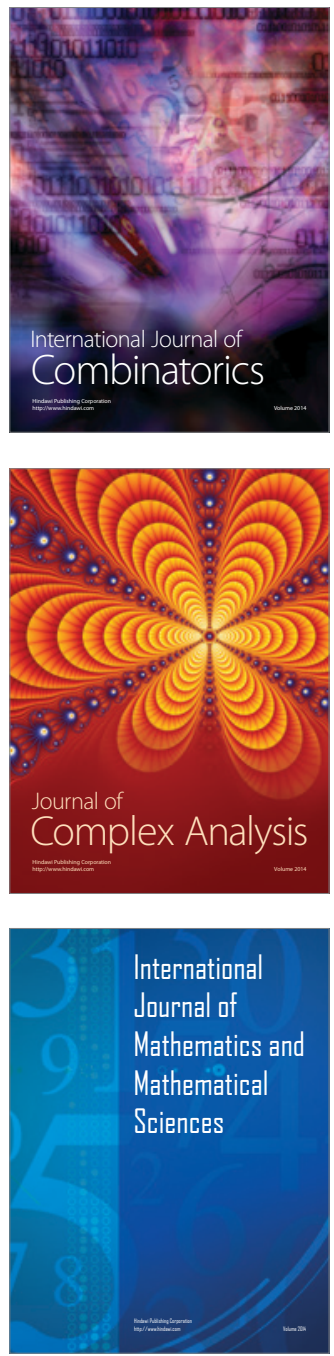
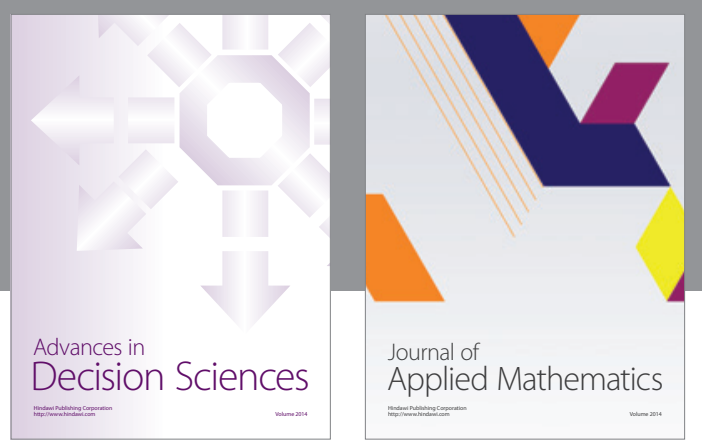

Algebra

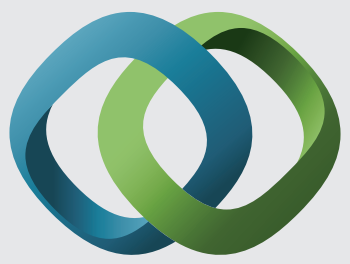

\section{Hindawi}

Submit your manuscripts at

http://www.hindawi.com
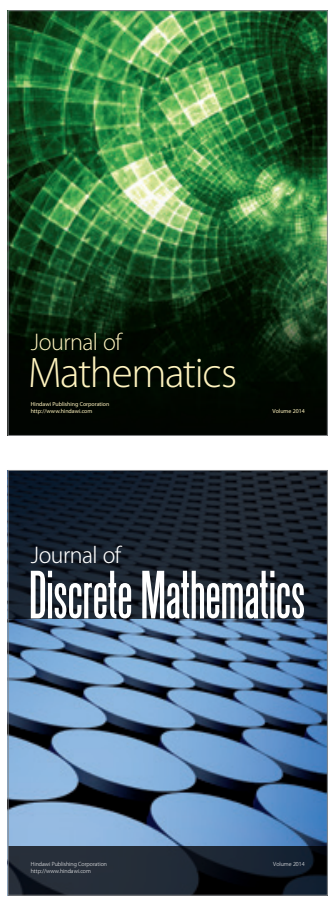

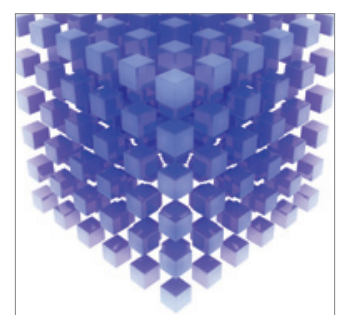

Mathematical Problems in Engineering
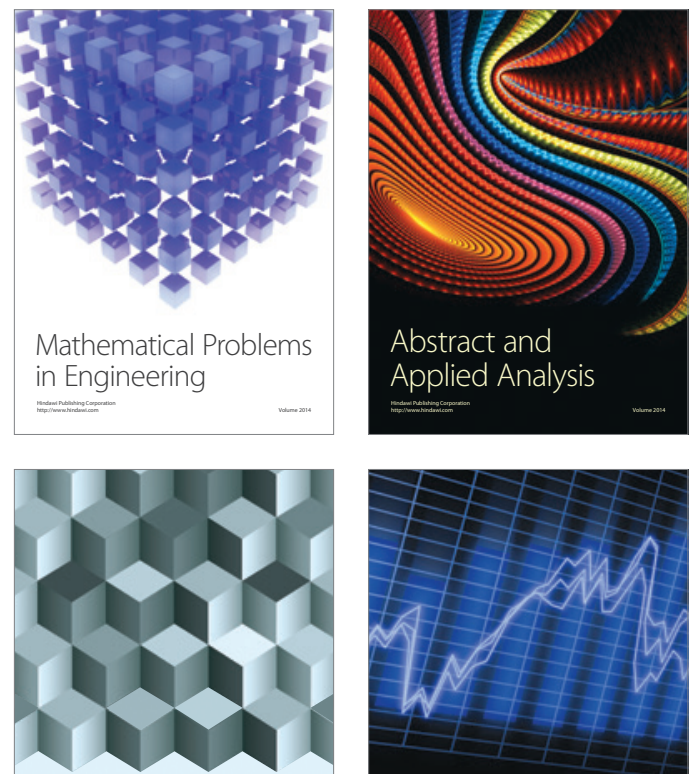

Journal of

Function Spaces

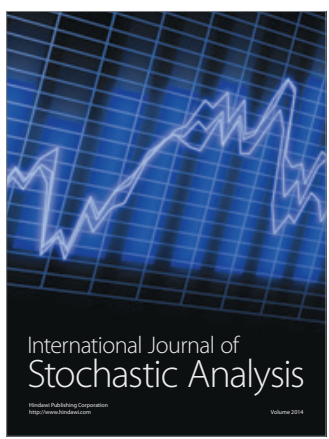

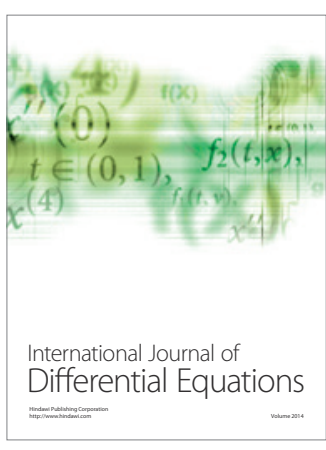
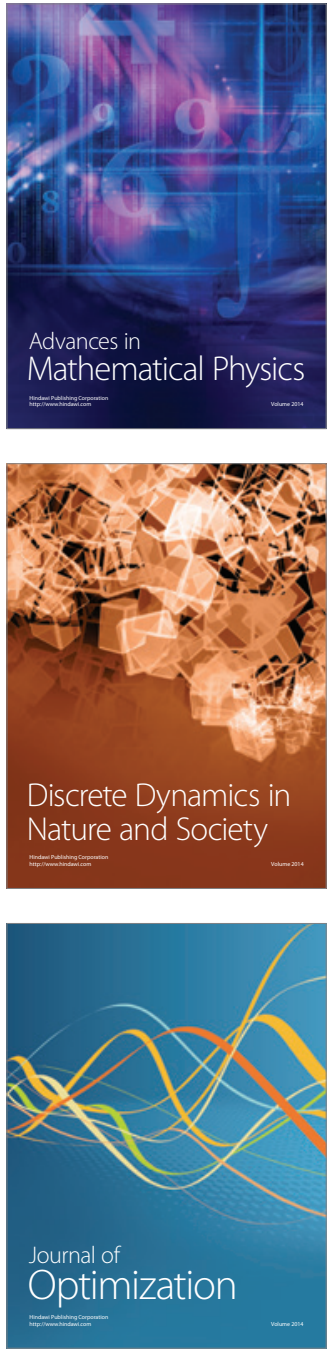